\title{
LA RECEPCIÓN DE HENRI BERGSON \\ EN EL PENSAMIENTO REACCIONARIO ESPAÑOL. \\ VITALISMO Y NACIONALCATOLICISMO EN JOSÉ \\ PEMARTÍN Y SANJUÁN (1888-1954)
}

The reception of Bergson thoughts in the Spanish reactionary thought. Vitalism and national-Catholicism in José Pemartín y Sanjuán (1888-1954)

\author{
ÁLVARO CASTRO SÁNCHEZ \\ GRUPO HUM 586 (Universidad de Cádiz) \\ alvaroc.s@hotmail.es
}

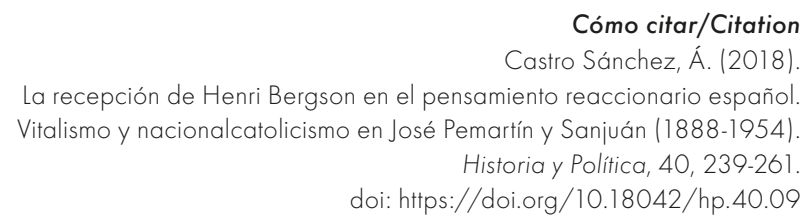

(Recepción: 15/06/2017. Evaluación: 15/09/2017. Aceptación: 01/11/2017. Publicación: 02/11/2018)

Resumen

El presente trabajo aborda la recepción del pensamiento de Bergson en el campo intelectual de la derecha española del periodo de entreguerras a través de la apropiación realizada por el filósofo nacionalcatólico José Pemartín y Sanjuán (18881854). Elaborado desde una perspectiva que hibrida diferentes disciplinas para ganar en reflexividad y capacidad analítica, se estudian los textos principales en los que el autor hizo un uso y defensa explícitos de la obra bergsoniana frente al liberalismo y el socialismo, pero también, al anatema que contra el filósofo francés se dispuso desde los sectores más intransigentes de la Iglesia. Así, se pretende mostrar la conexión del pensamiento reaccionario espańol con redes y debates internacionales y el uso de los bienes intelectuales que circulaban en estos para la legitimación filosófica 
de un discurso abocado a la fascistización durante los años treinta y que formará parte medular de las políticas franquistas.

\title{
Palabras clave
}

Bergson; José Pemartín; pensamiento reaccionario; modernismo religioso; nacionalismo reaccionario.

\begin{abstract}
The main topic of this paper is how the Spanish right-wing intellectuals during the interwar years embraced the philosophy of Henri Bergson by means of the previous borrowing made by the national-catholic philosopher José Pemartín y Sanjuán (1888-1854). Considering a conception of the History of Philosophy that also uses the social sciences to gain in reflexivity and analytical skills too, this work will study the main texts in which the author made an use and an explicit defense of Bergson's work against liberalism and socialism. But also the paper will make visible the anathema that the most intransigent sectors of the Church sentenced against this French philosopher. Thus, it will be shown the connection between Spanish reactionary thought and international networks and debate forums, as well as the use of intellectual goods that were circulating in these debates in order to philosophically legitimate philosophically a discourse bound to fascism during the thirties and which will form a core part of Francoist policy.
\end{abstract}

\section{Key words}

Bergson; José Pemartín; reactionary thought; religious modernism; reactionary nationalism. 


\section{SUMARIO}

I. INTRODUCCIÓN. II. UN SEÑORITO BERGSONIANO. III. LA PRIMERA RECEPCIÓN DE BERGSON Y EL MODERNISMO RELIGIOSO. IV. BERGSON EN LA UNIÓN PATRIÓTICA. V. LA CONFECCIÓN DE UNA POLÍTICA DE LA RELIGIÓN. VI. CONCLUSIONES. BIBLIOGRAFÍA.

\section{INTRODUCCIÓN}

La historia de España no puede seguir leyéndose al margen del contexto internacional y es importante que desde hace tiempo, en ámbitos o áreas diversas del campo historiográfico y sus afines, se esté rompiendo con el paradigma de su «excepcionalidad». Esto es especialmente prioritario respecto al periodo que se estudia en este trabajo, cuya historia del pensamiento filosófico y político es imposible de entender al margen de la coyuntura europea abierta desde la Gran Guerra y de los debates que circulaban por sus redes intelectuales. También es así para los sectores de la sociedad española supuestamente ajenos o enfrentados a la "extranjerización", posición a la que apresuradamente se asocia el pensamiento reaccionario hegemónico en la derecha española de aquellas décadas, que fundamentalmente enarboló la «teología política» del nacionalcatolicismo'.

Ninguna tradición intelectual sobrevive a la autarquía, es decir, si no se somete a una redefinición que la sintonice con los nuevos acontecimientos sociales, políticos o culturales intra y transfronterizos de su tiempo, aun cuando la meta sea mantener su matriz ideológica tradicional. Y ninguna actualización conceptual o terminológica es posible si sus agentes no se mantienen conectados con redes afines internacionales. Además, el intercambio entre redes intelectuales y sus procesos de emisión y recepción de teorías o conceptos puede ir acompañado, de forma relativamente independiente, de estrategias políticas compartidas. De tal modo, si bien ha sido habitual considerar el nacionalismo reaccionario español como una especie de nota distintiva respecto al fascismo europeo — es más, lo que vendría a «salvarnos» del totalitarismo, representación que actualmente se construye desde el llamado «revisionismo» franquista-, en realidad, aun con sus particularidades, formaba parte de un sujeto político europeo polifacético. Así, el historiador

1 González Cuevas (2001): 99-141. 
Ismael Saz ha señalado que al quedar apartada por el debate historiográfico acerca de la naturaleza del fascismo, y haberse estudiado de modo aislado, la cuestión del nacionalismo reaccionario necesita de un debate propio que dé lugar a un análisis más riguroso. Además, al mantenerse abierto el problema acerca de las ideas y creencias que movieron tanto a los fascistas como a los no-fascistas, existe una imprecisión conceptual importante. De tal modo, el «nacionalismo reaccionario» responde a una cultura política específica, conforma un complejo ideológico tan transnacional y tiene efectos históricos tan importantes como los del propio fascismo. Por lo tanto, se trata de un sujeto político-ideológico distinto del fascismo con el que, manteniendo elementos de proximidad, se vio obligado a aliarse en el terreno de la lucha social y política, como ocurrió en el proceso de fascistización que se desarrolló en las derechas españolas durante la II República y la Guerra Civil².

Ambas posiciones rivalizaron por la hegemonía en el campo europeo de la derecha hasta $1945^{3}$. En Italia, el nacionalismo reaccionario estuvo representado por la Asociación Nacionalista Italiana, en Portugal por Integralismo Lusitano y, en Francia, por Acción Francesa. En España el grupo que lo representó durante la II República fue el conformado en torno a la revista Acción Española, la cual dirigió Ramiro de Maeztu y en la que colaboró el filósofo José Pemartín. A este se dedica este texto, entre otros motivos porque su trayectoria intelectual se caracterizó por la constante actualización del discurso nacionalcatólico mediante la atención a las novedades filosóficas internacionales y a los descubrimientos científicos, así como a los bienes intelectuales de la derecha europea — incluida la fascista—. La trayectoria de aquella revista muestra, además, lo específico de la tradición teológico-política espańola, que si por un lado no terminó de asumir la herencia de Charles Maurras ${ }^{4}$, por otro lanzó puentes de diálogo con el fascismo, con el que confluyó, con tensiones, durante la Guerra Civil. Uno de esos puentes, en el sentido intelectual, fue el trazado por Pemartín con su particular apropiación del bergsonismo.

En un contexto de predominio del naturalismo y del positivismo, tanto Bergson como el pragmatismo norteamericano aportaban, desde finales del

2 Gallego (2014) señala que esa perspectiva es la adecuada para entender el espectro de la derecha antirepublicana y golpista que se termina agrupando en el partido único de FET y de las JONS en 1937.

3 Saz (2012): 155-190.

4 González Cuevas (1998): 87. Para profundizar en el conocimiento de la revista Acción Española puede verse Morodo (1985). Para la influencia de Maurras en dicho grupo, Olabarría Agra (1990). Sobre Maurras, véase Giocanti (2008). 
siglo XIX, una crítica a la idea de objetividad, señalaban los límites de la razón, reducían la capacidad de la inteligencia discursiva y subordinaban el conocimiento a razones técnicas o instrumentales, defendiendo a la intuición como la vía para una captación verdadera de la realidad'5 . Cabe recordar que el texto clásico que relacionó la obra de Bergson con el auge del pensamiento reaccionario propio de la burguesía fin de siècle desencantada con la modernidad fue el libro de Gyorgy Lukàcs El asalto a la razón (1953). El filósofo encontró en aquel, junto a Schopenhauer, Kierkegaard y Nietzsche, los referentes filosóficos de un asalto a las tradiciones de inspiración emancipatoria derivadas de la Ilustración. El irracionalismo contribuía a la defensa de una imagen del mundo "que, por debajo de la cautivadora apariencia de una movilidad viva, viene a restaurar en realidad el estatismo reaccionario", ejerciendo Bergson en Francia a comienzos del siglo xx la misma función que tuvo la influencia de Nietzsche en Alemania y el Imperio austrohúngaro en el espectro de la burguesía de derechas. Así, un ejemplo claro de la presencia de Bergson en la ideología de la extrema derecha francesa es su influencia en George Sorel, que fue su alumno. Para Sorel, su vitalismo fue una vía para liberar al marxismo de su racionalismo y su materialismo y opera en el centro de su teoría de los mitos sociales, según la cual se deben elaborar imágenes capaces de provocar el movimiento de las masas a través de la intuición. Explorando esa vía, el historiador Zeev Sternhell, mediante el análisis de la evolución intelectual de algunos sectores socialistas desde comienzos de siglo, ha señalado la influencia de Bergson tanto en Acción Francesa como en el tránsito que se llevó a cabo en Italia desde el socialismo al fascismo a través del sindicalismo revolucionario ${ }^{6}$.

Pemartín fue un caso singular en el marco de la recepción de Bergson en Espańa, el cual nos permite profundizar en las relaciones entre el modernismo y la radicalización de las derechas apuntada por autores como Roger Griffin 7 . Partiendo de ahí, el estudio de la posición del autor jerezano y su apropiación del pensamiento de Bergson puede contribuir a la tarea de profundizar acerca de las conexiones ideológicas entre la derecha autoritaria espańola y la del resto de Europa. Con ello, este trabajo traslada la necesidad de analizar las ideas filosóficas y los movimientos culturales en los que se gestó el fascismo al caso de la derecha golpista española. Esto se aborda desde un enfoque multidisciplinar que pone en diálogo al campo historiográfico con el filosófico.

\footnotetext{
Lukács (1972): 20.

6 Sternhell et al. (1994): 1-238.

7 Griffin (2010).
} 


\section{UN SEÑORITO BERGSONIANO}

Para analizar adecuadamente la recepción de filosofemas en un campo intelectual distinto al de donde fueron producidos, hay que tener en cuenta que ninguna importación se realiza desde cero, porque para ello se debe de contar con una disposición intelectual o cultural previa así como con unas condiciones sociales y materiales de posibilidad en el campo receptor. Del mismo modo, difícilmente se «recibe» una filosofía foránea si no se dispone de una línea autóctona con la que pueda enganchar. Así, el proceso de recepción no es pasivo por parte de los que incorporan determinados conceptos a su discurso, sino que requiere un ejercicio creativo de adaptación y uso en función del capital cultural, posiciones en el espacio social, así como las expectativas o circunstancias por parte de los agentes receptores. Teniendo esto en cuenta, el cometido de este y el siguiente apartado es esbozar la primera recepción del pensamiento de Bergson en España, con el objetivo de establecer después la posición de Pemartín respecto a la misma, si bien el espacio no nos permite desarrollar con mayor detalle la trayectoria vital que lo convirtió en un señorito culto y cosmopolita.

Nacido en Jerez de la Frontera el 29 de febrero de 1888 y perteneciente a una importante familia de bodegueros jerezanos — que era de antepasados franceses, de la región del Bearne- venida a menos a finales de siglo, Pemartín aprobó el Bachillerato en la Sorbona y acudió a los cursos de filosofía de Bergson en el Collège de France en 1904. Allí se impregnó del ambiente espiritualista que reinaba entre los jóvenes estudiantes católicos que encontraban en el vitalismo filosófico un asidero frente al reinante positivismo de tradición comtiana. Dos décadas después, tras haberse licenciado como ingeniero metalúrgico en París, hacerse cargo de la gerencia de las bodegas de la familia, así como casarse e instalarse en Sevilla, se vinculó con los círculos católicos conservadores del periódico sevillano El Correo de Andalucía, que llegó a dirigir en 1926, año en el que pasó a formar parte del Comité de la Unión Patriótica —el partido único de la dictadura de Miguel Primo de Rivera- de la capital andaluza. En 1927 fue elegido miembro de la Asamblea Nacional Consultiva y empezó a escribir asiduamente en La Nación, publicación destinada a legitimar ideológicamente al régimen y a propugnar un nuevo modelo de Estado inspirado en el corporativismo y el fascismo italiano. En esta militancia se encontró y colaboró con José Calvo Sotelo, Eduardo Aunós, Ramiro de Maeztu o José María Pemán, del que era primo-hermano. Desde entonces, desarrolló una intensa actividad de conferenciante «menor», especialmente en los espacios católicos y aristocráticos de Sevilla, publicando en 1928 Los valores históricos en la Dictadura española, obra de carácter apologético prologada 
por el dictador ${ }^{8}$. Tras la caída de este apareció como firmante del manifiesto fundacional de Unión Monárquica Nacional, partido que intentó agrupar a los primorriveristas y que estaba presidido por José Antonio Primo de Rivera, a quien conocía desde niño. Fue asimismo militante de Renovación Española durante la República, colaborando con la revista Acción Española desde su fundación y dirigiéndola durante la Guerra Civil, en cuyo proceso de convergencia de las familias políticas del golpe en un partido unificado publicó Qué es «lo nuevo», su obra más conocida. Durante la guerra desarrolló un importante papel de elaborador teórico, participando además de modo central en las comisiones de depuración del profesorado de enseñanza media y universitaria. Esto le procuraría el cargo de jefe del Servicio Superior de Enseñanzas Medias y Universitarias en el primer gobierno de Franco, del que dimitirá en 1942 por sus posiciones monárquicas. De modo que su despacho fue el centro neurálgico por el que pasaron los expedientes de depuración y las posibles rehabilitaciones en los años más intensos de la represión. Tras su ingreso dentro del consejo asesor del Instituto Luis Vives de Filosofía del C.S.I.C., acentuó su atención a la filosofía de la ciencia desde una perspectiva neotomista. Eso sí, siempre mantuvo una constante reflexión acerca del tiempo personal, físico y ontológico basándose en la larga serie de novedades científicas y filosóficas que se ocuparon de dichas cuestiones entre los años 1920 y 1950: esa fue su vía para singularizarse intelectualmente en el ambiente en el que se movió y Bergson no dejó de jugar nunca un papel central. La culminación a su trayectoria llegaría en 1949, cuando pasó a dirigir la Federación de Amigos de la Enseñanza, y en 1951, al ingresar en la Real Academia de Ciencias Morales y Políticas. Fallecería en Madrid tres años después9.

Pemartín era un lector libre alejado del modelo teologal del filósofo seminarista que se impondrá en el primer franquismo. Combinaba banquetes en el Ritz, con la burguesía industrial madrileña, o visitas al Coto de Doñana, con la aristocracia andaluza, con las conspiraciones políticas y la lectura y escritura filosófica. Sus elaboraciones pueden dividirse en tres líneas: una, que muestra los límites de su discurso, son los programas políticos de los partidos en los que militó, las directrices que se desprenden de las encíclicas papales de León XIII (Rerum novarum) y de desarrollos teológicos como los de Jaime Balmes, Zacarías de Vizcarra o el pensamiento del carlista Vázquez de Mella; otra, que armaba de actualidad su discurso y ponía al pensamiento reaccionario español en relación con la filosofía europea de su tiempo, atendía a Nietzsche, Bergson, Ortega, Heidegger o Scheler, en la medida en que eran autores

8 Una primera aproximación biográfica en Quiroga Fernández (2007).

9 Castro (2018). 
que ponían de relieve la crisis de la razón moderna. En tercer lugar, prestó especial atención a la filosofía de la ciencia francesa que va desde Henri Poincaré y Pierre Duhem hasta Gastón Bachelard, pasando por León Brunschvig y Émily Meyerson, a quienes utilizó como arma de desmontaje de las pretensiones del positivismo y de correctivo hacia las implicaciones filosóficas de la física de Albert Einstein, que consideró una culminación del cartesianismo, origen de la banalidad materialista y mecanicista. En este conjunto de influencias primó la «marca Francia» y dentro de este espectro es donde hay que situar su interés por la filosofía de Bergson, del que se convirtió en su principal receptor en el subcampo intelectual de la derecha española.

\section{LA PRIMERA RECEPCIÓN DE BERGSON Y EL MODERNISMO RELIGIOSO}

Desde un primer momento, la filosofía de Bergson se recibió en España en campos muy diferenciados. Dejando a un lado la influencia en la literatura a través de autores como Clarín, Pérez de Ayala o Antonio Machado, desde el punto de vista de la historia de la filosofía española la primera obra que contó con cierta resonancia fue L'Evolution Créatrice, de 1907. Esta se leyó desde prismas antagónicos. Por ejemplo, los institucionistas se sintieron atraídos por sus vínculos con el pragmatismo norteamericano e incorporaron - consciente e inconscientemente- algunos de los filosofemas bergsonianos a su defensa de la reforma pedagógica. Sin embargo, los sectores eclesiásticos, más que al pragmatismo, atendieron a los aspectos metafísicos de la obra de Bergson, viendo en esta una perversión de la ortodoxia católica asociada al modernismo religioso, cuya polémica explosionó en Francia justamente el mismo año en el que aquella obra se publicó.

El llamado «modernismo religioso" fue un movimiento surgido en el seno del catolicismo que se caracterizó por buscar la renovación de la Iglesia a través de una postura receptiva hacia lo espiritual, en términos vitalistas e irracionalistas. La reacción modernista francesa encontró en el bergsonismo una salida filosófica a las inquietudes renovadoras que recorrían seminarios e institutos de teología, convirtiéndolo en la base de un espiritualismo que convencía a muchos jóvenes poco atraídos por la teología escolástica. Un ejemplo muy ilustrativo es el relato que de dicho ambiente hizo el eminente medievalista Étienne Gilson. Admirador de las primeras obras de Bergson, reconoció que su ataque al cientifismo, el materialismo y el determinismo fue un acontecimiento decisivo para los jóvenes católicos dedicados a la filosofía de su tiempo. Mostrando dicho desencanto con la escolástica, recordaba: 
Criticismus refutatur, positivismus refutatur, era demasiado fácil; al hacer, de una manera abierta, profesión de rechazar a priori como falsa toda doctrina filosófica cuyo espíritu o conclusiones contradijeran las verdades de la religión cristiana, tenían, se sabía, teológicamente razón para condenar a sus adversarios, pero no siempre se sabía por qué éstos estaban filosóficamente en lo falso. La llegada de Bergson al campo de batalla cambió el sentido y las condiciones del combate. Cuando el nuevo campeón entró en la liza, la negación de la metafísica en nombre de la ciencia moderna se vio contrarrestado por las afirmaciones contrarias de una metafísica situada en la prolongación exacta de esta misma ciencia. El positivismo estaba derrotado por un espíritu más positivo aún que el suyo. Al mostrarse más exigente que ellos en materia de ciencia, Bergson acababa de realizar una innovación triunfal en el criticismo y el cientifismo ${ }^{10}$.

La memoria de Pemartín de sus años de estudiante en París, que evocará en distintas ocasiones, ayuda a entender su afición por un filósofo francés que también será anatemizado más adelante, por su origen judío y su condena del Régimen de Vichy, por el franquismo:

Con una gran emoción las jóvenes generaciones francesas del principio del siglo $\mathrm{xx}$, entristecidas por una herencia de pesimismo nietzscheano y de positivismo materialista, acudían a las lecciones del maestro, titular de la Cátedra de Filosofía del Collége de France, y bajo el encanto de la palabra más elegante y la más maravillosamente coloreada, veían al espíritu — casi desterrado hacía cincuenta años de los cursos de filosofía-, surgir finamente del análisis de los primeros estados de la conciencia, de esa sutil puerta del espíritu que se llama la memoria, que detiene o deja pasar misteriosamente el flujo intermitente de nuestros recuerdos, de nuestros pensamientos, de nuestros ensueńos... ${ }^{11}$.

El primero en trasladar el intuicionismo del filósofo francés al campo de la teología fue Edouard Le Roy, que acabó siendo sucesor de la cátedra de Bergson en el Collège de France. En este centro también impartía clase el historiador del cristianismo Abbé Loisy, que desató la crisis modernista con su obra El Evangelio y la Iglesia (1902) ${ }^{12}$.

La condena al modernismo se abrió con la encíclica Pascendi de Pío X promulgada en 1907. En ella se proclamaba, desde una defensa férrea del

10 Gilson (1962): 135-211. Agradezco al profesor José Luis Cantón la referencia.

11 Pemartín (1934b): 600-601.

12 Vidler (1970): 20-108. 
tomismo, la posibilidad de un conocimiento racional de Dios y se condenaban las ideas kantianas, pero implícitamente, también las bergsonianas. La encíclica no venía sola, sino que el Vaticano publicó en 1910 el Motu Propio Sacrorum Antistitum, por el que se imponía un juramento antimodernista a los futuros miembros de la Iglesia, afirmando que los estudios sacerdotales solamente debían de contemplar la filosofía escolástica, produciéndose así una purga de los seminarios y facultades católicas de los simpatizantes con el modernismo. Más específicamente, el bergsonismo, entendido como una filosofía de la «inmanencia vital», fue condenado por el Vaticano en 1914, contando con duras críticas desde el campo teológico, como las de Jacques Maritain en su La philosophie bergsonienne, de aquel mismo año. En España se hicieron eco del anatema la mayor parte de la prensa, libros e instituciones ligadas a la Iglesia y al catolicismo social (El Debate, $A B C \ldots$..., que reprodujeron la condena contra la obra y persona del filósofo y orquestaron una campaña de desprestigio contra la degeneración espiritualista en la que desembocaba. Si bien al bergsonismo se acercaron católicos liberales como Maeztu, Miguel de Unamuno o Juan Domínguez Berrueta — estos dos últimos eran amigos de intelectuales cercanos a Bergson como François Chevalier y Maurice Legendre-, autores como los padres Marcelino Arnáiz, Eustaquio Ugarte de Ercilla o José Cuervo lo criticaron duramente ${ }^{13}$. Además, a la imagen negativa construida desde los sectores más conservadores de la sociedad española contribuyó la noticia de su visita en mayo de 1916 con la misión diplomática de decantar la neutralidad del país hacia los aliados. Aquella estaba organizada por el Instituto de Francia y le acompañaron Imbart de la Tourt, Edmond Perrier y Charles-Marie Widor, siendo recibidos por el propio Alfonso XIII. De la misma dio noticias la prensa madrileña, así como de las conferencias que el filósofo impartió en el Ateneo y la Residencia de Estudiantes. Presentadas por José Ortega y Gasset, fueron traducidas e introducidas por Manuel García Morente — quien también había tratado a Bergson en sus tiempos de estudiante en París-y publicadas como libro aparte por la revista España.

Respecto a Ortega, los enlaces con Bergson son importantes, y se podían establecer en tres puntos que, a su modo, repetirá Pemartín. En primer lugar, compartían una concepción amplia de la filosofía, que dialogaba con las ciencias; en segundo, la "lealtad a lo real», lo concreto e individual, y por último, situaban a la vida como fenómeno central de reflexión ${ }^{14}$. Pero Ortega se desmarcó de la versión bergsoniana del vitalismo en su conocido texto Ni vitalismo, ni racionalismo, que publicó en la Revista de Occidente en 1924. En este

13 Lacau St Guily (2010): 244 y ss.; Lacau St Guily (2015).

14 Atencia (2003): 67-98. 
encontraba tres líneas del vitalismo filosófico. Una sería propiamente biologista y es la que estaba representaba por las obras de Avenarius, Ernst Mach y el pragmatismo, la cual reducía el conocimiento a un proceso meramente biológico. En segundo lugar, y esta sería la versión de Bergson, estaba la filosofía que defendía que la razón no era el modo superior de conocimiento, y que frente al "conceptualismo» propone la intuición, donde se «viven» las cosas sin distanciarlas analíticamente. A esa «intimidad transracional con la realidad viviente ${ }^{15}$ es lo que Bergson llamaba «intuición». Sin embargo, la posición de Ortega pone a la «vida» en el centro de la reflexión filosófica, pero no menosprecia a la razón, sino que es crítico con el racionalismo, resultando en el raciovitalismo.

A pesar de lo dicho y siendo cierto que tenía muy presente la obra de Ortega, es difícil establecer vías directas dentro del campo filosófico o político españoles a través de las cuales Pemartín recibiese esa posición filosófica y la incorporase a su discurso reaccionario, poniendo el intuicionismo al servicio de la defensa de los valores tradicionalmente esgrimida por los pensadores ultracatólicos españoles; valores que, resumidos en el lema carlista «Dios, Patria y Rey», eran los propios de la representación del "orden» social que primaba en la burguesía reaccionaria de la que provenía. Lo lógico, especialmente por su vinculación a la Asociación Católica Nacional de Propagandistas, hubiese sido su adhesión a la condena del bergsonismo por parte del Vaticano, pero no fue así. Más adelante se verá su explicación al respecto, pero tiene mucho que ver con que Pemartín, que contaba con un importante patrimonio familiar, nunca aspiraría a una carrera académica en el mundo de la filosofía y por tanto se tomaba licencias no adecuadas para quien sí tuviese que hacerlo, sobre todo si quería realizarla por los canales eclesiásticos - las trayectorias de los filósofos Xavier Zubiri, que hizo el juramento antimodernista, lo que vivió con profunda desolación, o la de Juan David García Bacca explican mucho al respecto- - En cualquier caso, había una brecha que permitía jugar con el vitalismo bergsoniano dentro del marco de posibilidades que aquella condena permitía. Esa era la posición mantenida por el sacerdote Juan Zaragüeta, quien trató, como dice Camille Lacau St Guily, de reconciliar lo irreconciliable ${ }^{16}$.

Aunque al comienzo se mantuvo cauto, repitiendo las tesis que el cardenal Mercier publicó en 1908 advirtiendo sobre la peligrosidad de las lecturas modernistas, su interés por la psicología llevó a Zaragüeta a incorporar poco a poco ideas fundamentales de la filosofía de Bergson, a quien acabará

15 Ortega y Gasset (2005): 717.

16 Lacau St Guily (2010): 375-380. 
dedicando una amplia monografía en la significativa fecha de $1941^{17}$. Lo cierto es que este sacerdote, uno de los popes de la filosofía y la pedagogía académicas de las dos primeras décadas del franquismo, representa como pocos a la saga de pensadores del orbe católico que estuvieron especialmente preocupados por la relación entre la ciencia y religión. Muy influyente en la carrera de Zubiri, este filósofo también donostiarra caracterizó su carrera filosófica y teológica por la ambición de reconciliar las ciencias contemporáneas con el neotomismo enseñado en la Universidad de Lovaina, reconciliación en todo caso en la que las primeras debían de quedar insertas en el marco de la teología natural o, al menos, dominadas simbólicamente. Este enfoque impregnará más adelante parte de la actividad investigadora del Instituto Luis Vives de Filosofía del C.S.I.C., que dirigió durante la década de los 1940 y en el que Pemartín será consejero, tal y como se ha dicho.

Entender ese sesgo "modernista" en el seno del propio catolicismo es importante para delimitar el uso de las ideas de Bergson por parte del jerezano, pero no es suficiente. Hasta donde sabemos, el jerezano no siguió ninguna maestría dentro del campo filosófico español para recibir y usar esa filosofía, sino que hacía una lectura propia, más situado en relación directa con el campo intelectual francés y sus redes de intelectuales derechistas y católicos que con el español, emulando por tanto la lectura que podían hacer otros lectores de disposición autoritaria en otros países europeos.

Para Permartín, Bergson se sumaba a unos signos de cambio más generales que probaban el derrumbe y superación del racionalismo: la crisis de la física clásica a manos de la mecánica cuántica, el auge de la teoría de los valores objetivos de Heinrich Rickert o la axiología de Max Scheler, la filosofía de Herman Cohen y Edmund Husserl, etc., que junto al vitalismo levantaban acta del fin de la modernidad y con ello, de todo lo que le estaba asociado, desde el racionalismo al positivismo, desde el liberalismo al socialismo, todo ello pensado siempre desde una concepción «salvaje» — es decir, no erudita, no amaestrada académicamente, y a su vez, maniquea y profundamente guerrera- de la historia de la filosofía. Así, en sus primeros textos se encuentran términos bergsonianos que conocía desde antes de la polémica modernista y que usaba teniendo como objetivo fundamental el combate político, que en el contexto español de recepción de tales ideas incluía, de suyo, la cuestión religiosa. Si el enemigo fundamental era el idealismo en política, en tanto que estaba asociado a las aspiraciones democráticas del liberalismo y del igualitarismo socialista, la obra del francés también le servía para plantear una teoría aristocrática del conocimiento, con la legitimación de las jerarquías

17 Zaragüeta (1941). 
sociopolíticas que le acompañaban. Por tanto, si bien es importante tener en cuenta los prismas señalados respecto a la recepción de Bergson en Espańa y su cercanía con la línea particular de Zaragüeta, hay que indicar que el jerezano llevó a cabo una incorporación propia del bergsonismo a su actividad ideológica e intelectual. Y en dicha apropiación que comienza en los años veinte va a primar una concepción irracionalista, tanto de la filosofía como de la política, cuyos paralelismos, y a falta de un estudio más sistemático de las redes intelectuales en las que se desenvolvía, se pueden observar más claramente fuera de España. Por ejemplo, con la influencia de Bergson en Georges Sorel ya indicada, en Charles Maurrás ${ }^{18}$, en el futurismo italiano, en Giovanni Gentile o en el propio Benito Mussolini.

\section{BERGSON EN LA UNIÓN PATRIÓTICA}

Ya se indicó que una vez instalado en la capital de los señoritos del sur, desde 1926 Pemartín empezó a publicar cada dos semanas en el órgano de prensa y propaganda del régimen de Primo de Rivera, el citado diario La Nación ${ }^{19}$. Además de una larga serie de artículos, la principal obra en este periodo fue el libro Los valores históricos en la dictadura española ${ }^{20}$. Este estaba destinado a subrayar los logros económicos, estructurales, sociales, sanitarios, educativos, etc., de la dictadura. En su «Introducción» se adhería a una visión concreta de la historia de la nación española promovida desde los sectores más intransigentes de la Iglesia. Como se sabe, dentro de la ideología nacionalcatólica tiene un peso específico la representación de cierta Historia de España, invención que no se puede rastrear únicamente en el tiempo medio del siglo $\mathrm{xx}$, sino que se vino gestando desde hacía mucho. No obstante, la cuestión del legado cultural español del Siglo de Oro había relanzado aquella al ser utilizada dentro de la batalla ideológica contra el krausismo en la conocida disputa sobre la ciencia española por la que Menéndez Pelayo se enfrentó a la Institución Libre de Enseñanza, reviviendo un debate ya presente a finales del siglo XVIII. El santanderino, como se sabe, defendió la postura catolicista al considerar que los momentos más vigorosos de la nación espańola coinciden cuando la Iglesia y el Estado han sido más intransigentes e inquisitoriales hacia lo extranjero. Por esa vía, la memoria menéndez-pelayista que en la Espańa posterior será objeto de pugna por su patrimonialización entre nacionalistas

\footnotetext{
18 Antliff (1993): 169-184.

19 Una síntesis temática en López Íñiguez (2010).

20 Pemartín (1928).
} 
reaccionarios y falangistas reclamará a la teología como base doctrinal de un pensamiento español genuino. No obstante, como ha puesto de relieve Pedro Cerezo, pocas de las reflexiones o disputas dentro del entramado ideológico-espiritual de los intelectuales españoles desde finales del siglo XIX, comenzando por la generación del 98, pueden entenderse al margen de la crisis de la modernidad europea ${ }^{21}$, siendo el modernismo espiritual una de sus expresiones.

Si por una parte una crisis civilizatoria provocada por la Gran Guerra atravesaba el continente minando los principios de la democracia liberal, por otra, en el campo científico, los nuevos descubrimientos a partir de Einstein y la teoría atómica amenazaban la seguridad de la concepción moderna y newtoniana del mundo. Así, en su etapa de La Nación, Pemartín encontraba en la crisis de la física clásica una base argumental para arremeter contra el liberalismo y la democracia, al hacerlos herederos del racionalismo kantiano y rousseniano, y en última instancia, del cartesianismo. De ese modo, la democracia parlamentaria constituye uno de los momentos de mayor degeneración o desnacionalización de España. Según Pemartín, el siglo xix estaba representado por dos escuelas de pensamiento distintas. Por un lado la «inmanentista», derivada del kantismo, que suponía la moral del imperativo categórico trasladada al derecho. Concretada de manera formal en Rousseau y la Revolución francesa, el inmanentismo pretendía que la verdad política y la legitimidad del Gobierno fuese producida por la masa, desde dentro de la «opinión pública». Por otro lado, el trascendentalismo, representado por el tradicionalismo, establecía un orden trascendente desde fuera de la masa y que da sentido a las acciones de la misma. Ese trascendentalismo era una vía "realista" para la solución de los problemas políticos ocasionados por la herencia ilustrada.

La acusación al «apriorismo» kantiano como origen del fanatismo político propio del socialismo será muy habitual en Pemartín. En él se basarían tanto los principios absolutos de la ciencia física, que reduce la consideración de todo lo real a meras categorías cuantitativas, como los de la soberanía absoluta del pueblo; «ucronismos», expresión de Ortega, que se derrumbaban a mediados de los años veinte. Muy influido por España invertebrada, consideraba que el irracionalismo era la corriente que debería comandar la nueva ideología política europea. Y lo cierto es que en sus textos de La Nación ${ }^{22}$, las referencias a conceptos tomados de Ortega se cruzan con los de Bergson, de

21 Cerezo Galán (2003): 23-50.

22 Al respecto, destacan «Reintegración de lo dislocado», La Nación, 18-11-1926; «Las ideas de nuestra política», La Nación, 31-1-1927; «Ídolos y máscaras», La Nación, 26-2-1927; "Más allá del racionalismo», La Nación, 14-6-1927; «La libertad colectiva», La Nación, 15-10-1927; «La muerte de una clase», La Nación, 22-11-1927; «La 
quien adopta las distinciones entre cualidad y cantidad, homogeneidad y heterogeneidad, espacialidad y temporalidad, así como el «intuicionismo» como clave explicativa del «ser» de los españoles.

Los principales ejes de la filosofía de Bergson son los conceptos de «intuición» y «duración», que desarrolló a la contra del análisis positivista de los fenómenos psíquicos. La razón científica reducía el tiempo a una forma de espacio al estudiar los hechos de conciencia como si de hechos físicos se tratase, midiéndolos de modo cuantitativo y ordenándolos mediante la ley de sucesión, al modo de cómo se ordenan los objetos espacialmente. Sin embargo, hay que diferenciar entre un tiempo espacializado, que construyen la ciencia y la razón geométrica, del tiempo auténtico, que es el de la «duración» en la vida interior de la conciencia y en el que los momentos no pueden diferenciarse como estados distintos y continuos. De modo que no es posible medir ninguna vivencia interior de la conciencia, sea la representación, la volición o la memoria ${ }^{23}$. De tal modo, la «duración» es un tiempo irreversible e imprevisible ante el cual las categorías del pensamiento racional se quedan cortas: se vuelve inobjetivable científicamente. Pero además, se corresponde con el tiempo real de las cosas. Solamente el método de la «intuición» puede alcanzarla, la cual se convierte en el camino para la restauración de la filosofía como ciencia primera. Esa era la vía por la que el intuicionismo se disponía por parte de religiosos como Zaragüeta, dada su viabilidad para contrarrestar el predominante papel de las explicación científica al modo positivista.

En un primer momento, Pemartín incorpora la idea de «intuición» a su concepción psicologista del pueblo español. Este siempre la ha llevado consigo, en tanto que percepción directa de la «esencia de los fenómenos y las cosas», como a priori en su relación práctica con el mundo. Ese «realismo» es un rasgo que define la excepcionalidad de la inteligencia mediterránea. Así que frente al "conceptualismo» de los pueblos del norte, los pueblos mediterráneos «con nuestro intuicionismo sintético meridional practicábamos la cosa» $»^{24}$. La «intuición» sería un camino corto, un atajo para llegar a lo que está fuera. De ese modo defiende un «intuicionismo» mediterráneo frente al "conceptualismo» nórdico, pues Benito Mussolini está demostrando que en tiempos que demandan acción y vitalidad, los pueblos latinos están más cerca de la realidad. El pueblo español es intuitivo y nada conceptual, por lo que la tradición inmanentista del liberalismo $-\mathrm{y}$ con ello el debate

realidad velada», La Nación, 29-3-1928; «Las dos escuelas», La Nación, 4-4-1928; «Los médicos de Molière», La Nación, 16-5-1928.

23 Bergson (1973): 15 y ss.

24 Pemartín (1928): 595-598. 
parlamentario- como doctrina política es imposible que encuentre compatibilidad con la "psicología nacional».

Este punto pone en relación la crítica al igualitarismo social con la fundamentación de una visión jerárquica del acceso a la verdad. Como señaló Lukàcs:

[...] la posición central asignada a la vivencia en la teoría del conocimiento de la filosofía de la vida inculca necesariamente una actitud aristocrática. Una filosofía de la vivencia sólo puede ser intuitiva, y la capacidad de intuición es, al parecer, patrimonio de los elegidos, de los miembros de una nueva aristocracia. Andando el tiempo, a medida que se agudicen todavía más las contradicciones sociales, se proclamará abiertamente que las categorías del entendimiento y la razón son las que corresponden a la chusma democrática y que los hombres realmente escogidos y superiores sólo se asimilan el mundo a base de la intuición. La filosofía de la vida profesa, por principio, una teoría aristocrática del conocimiento ${ }^{25}$.

Esa «teoría aristocrática del conocimiento» desembocaba en la negación de la política en favor del pragmatismo tecnócrata y del decisionismo autoritario que en su día defendió Donoso Cortés. Frente al utopismo liberal, el Estado debía de regirse por una organización más técnica y eficaz, que acabase con el debate político. Así que cuando Pemartín toma el intuicionismo bergsoniano como instrumento justificador de un Estado contrarrevolucionario no hacía más que sumarse a un asalto a la modernidad ilustrada presente en toda Europa. Entre sus rasgos se hallaron la sobrevaloración de la acción y la defensa, desde postulados vitalistas, del decisionismo y de la legitimidad de la violencia.

\section{LA CONFECCIÓN DE UNA POLÍTICA DE LA RELIGIÓN}

Tras la caída de la dictadura y la llegada de la II República, mientras militaba en los partidos de la extrema derecha alfonsina y antidemocrática, Pemartín participó en la revista Acción Española. Con esta publicación clave del pensamiento ultraconservador del siglo xx español, imprimió textos sobre problemas de actualidad política, científica, literaria y filosófica. Así, uno de los artículos que ha sido citado en ocasiones es la crítica a la que sometió la

25 Lukács (1972): 334-335. 
interpretación orteguiana de la física de Einstein $^{26}$. En su día, el filósofo madrileńo asoció la teoría de la relatividad con el declive de la filosofía moderna, del racionalismo y de la física de Newton, al acabar con la idea de un tiempo y espacio absolutos. La relatividad implicaba la desaparición de una idea propia del sentido común: la de suponer una simultaneidad universal en los fenómenos físicos, ya que demostraba que lo que puede ser simultáneo desde un sistema de referencia A (un observador, por ejemplo), no tiene por qué serlo en un sistema de referencia B. De ese modo, la simultaneidad universal de Newton se convertía en simple convención. Interpretada así, Ortega veía confirmada su idea defendida en El Tema de nuestro tiempo de que era la propia realidad la que se daba como perspectiva ${ }^{27}$.

Pemartín, interesado en desprestigiar a un filósofo considerado entonces un precursor de la República, escribió que Ortega se precipitaba al considerar a Einstein como una superación del cartesianismo, porque más bien representaba la culminación de la aspiración fundamental de este: el sustituir una consideración realista y cualitativa de la realidad por un nominalismo matemático absoluto. En esta crítica, una de las pocas que recibió Ortega en este punto, Pemartín se apoyó en la confrontación que el propio Einstein tuvo con Bergson años antes. El francés había tomado contacto con las teorías del físico en el Congreso Internacional de Filosofía de Bolonia de 1911 a través de una exposición del físico Paul Langevin ${ }^{28}$. En abril de 1922 ambos se encontraron en la Sociedad Francesa de Filosofía, en la que se celebró un encuentro en el que además de Langevin también estuvieron Léon Brunschvig, Eduard Le Roy y Émile Meyerson. Meses después Bergson publicó Durée et simultainéité, donde aparecían una serie de críticas abiertas a Einstein, comenzando un debate entre ambos que duró toda la década. Lo cierto es que el francés asumía una posición dualista que Pemartín y Zaragüeta explotaron sucesivamente, aún cuando el propio filósofo la fue atenuando.

Por una parte, habría un mundo atemporal, objetivo-material, extenso y por tanto mensurable; pero por otra, un mundo subjetivo, psicológico e inextenso que sería el de la «duración» en la conciencia y al que la ciencia no podía acceder de modo positivo. Entre otras cosas, eso permitía defender un espacio para el espíritu en términos de dualismo antropológico, así como un papel salvífico de la filosofía frente al naturalismo cientificista.

La idea de una realidad dinámica y que se realiza temporalmente, que «es» tiempo, es algo que obsesionó a Pemartín el resto de su vida. En su obra

26 Pemartín (1932): 131-146.

27 Ortega y Gasset (2005): 642-652; al respecto, véase Castro Sánchez (2013).

28 Bergson (2004): 8 y ss. 
Introducción a una filosofía de lo temporal, escrito en 1936, criticaba las visiones estáticas y cuantitativas del cosmos tradicionales, cuya última versión, que suponía el agotamiento del pensamiento occidental, era la física moderna por haberse limitado a lo puramente espacial. Pemartín hablaba de una «metástasis» del pensamiento occidental que iba más allá de la actitud estática del idealismo que Einstein repetía, en una línea de defensa de lo cualitativo que partía de Nietzsche y Bergson y a la que se sumaban Scheler y Heidegger ${ }^{29}$. Pero fue en Acción Española donde de modo concreto se ocupó de la filosofía de Bergson, sobre todo en dos textos. Uno de ellos estuvo dedicado a comentar la correspondencia de Bergson con William James en Revue de Deux Mondes, y el otro se trata de un largo análisis de la obra Les Deux Sources de la Morale et de la Religion (1932). Comenzando por el primero, el punto de unión entre los primeros libros de Bergson con los Principios de psicología o Pragmatism de William James fue haber hecho de la vida, a comienzos de siglo, una verdad total inalcanzable para la razón moderna ${ }^{30}$. De cara a los objetivos concretos que perseguía entonces la revista — que, entre otras cosas, secretamente recaudaba dinero, tejía redes y conspiraba por el fin de la República一, Pemartín encontraba tres aspectos de interés que nos aclaran notablemente la lectura que hizo de la misma. El primer punto es la relación del bergsonismo con la ortodoxia católica. Recordando cómo desde sus comienzos la filosofía de Bergson fue duramente atacada por filósofos católicos, reconocía abiertamente que su obra se situaba del lado de la heterodoxia religiosa. Ahora bien, es preciso ubicarla correctamente. Los puntos más graves que llevaron a su condena fueron los tintes monistas y panteístas de L'Évolution créatrice, su marcado "antiintelectualismo» $y$, por último, la continuidad entre la materia y el espíritu que Maritain criticó a Bergson por su obra Matière et mémoire. Essai sur la relation du corps à l'esprit. Respecto al primer punto, Pemartín se mostraba especialmente preocupado por salvar a Bergson de la acusación de heterodoxia.

El jerezano se reconocía parte de aquella generación de 1900 compuesta de estudiantes franceses que, viendo agotadas sus energías ante el predominio del positivismo, encontraron en Bergson un soplo de aire fresco y una vía de defensa de lo espiritual. Eso es algo que reprochó a la Iglesia no haber asumido con inteligencia, como también hará Gilson en la obra citada al principio de este trabajo, porque no supo ver que su filosofía abrió un camino espiritualista para la religión católica. Su mérito fue demoler las bases del positivismo desde su propio terreno, desde el lenguaje propio de las ciencias

29 Pemartín (1941): 160-161.

30 Pemartín (1934a): 594-595. 
experimentales y no desde el lenguaje de la «escolástica», solamente accesible para un grupo de «iniciados», lenguaje que obviamente no podía ser del gusto de las juventudes universitarias de aquella época.

En segundo lugar, en el núm. 66 de Acción Española, dedicaba de nuevo unas líneas a la relación del bergsonismo con la filosofía tomista con motivo de la publicación de Les Deux Sources de la Morale et de la Religion (1932). Para ello no recurría a Zaragüeta — al que no citaba-, sino a algunos autores franceses que desde la ortodoxia católica habían indagado esa vía, como el Padre Sertillanges, mostrando bastante conocimiento de la bibliografía que tanto el bergsonismo como el antibergsonismo habían generado en el país vecino. Cabe recordar que lo que llevó a colocar en el índice de libros prohibidos las obras de Bergson en 1914 fue su "peligro modernista». Sin embargo, para Pemartín «Dios elige los caminos que quiere» y la Iglesia no debe de tener una filosofía propia. Es más, la filosofía bergsoniana «ha hecho, en conjunto, mucho más bien que mal ${ }^{31}$. Basándose en el ejemplo de Maritain y sus cambios en la edición de su monografía sobre Bergson de 1930, recuerda que los filósofos católicos han ido modificando su posición inicial, destacando la obra de E. Rideau. Así que si bien Bergson no se ajusta a la ortodoxia católica, cabe situarlo en una "heterodoxia relativa» que abre la puerta a una vía espiritualista o misticista hacia la religión. Además, sobre la acusación de «antiintelectualismo» hay que preguntarse realmente si lo de Bergson es una posición antiintelectualista o más bien un antirracionalismo exagerado. De modo que, aun siendo profundamente diferente al intelectualismo tomista, cabe un punto de contacto.

Respecto a la cuestión de la continuidad entre materia y espíritu que Maritain reprochó a Bergson acusándolo de "panteísta», hay que recordar que este hacía del cerebro un instrumento de la conciencia en el que la inteligencia se ponía a resolver cuestiones prácticas, siendo privilegio del espíritu la comprensión y el propio pensamiento — la representación-. Sería la memoria el punto de enlace, de flujo, entre la mente y el cerebro. Recuerda que la síntesis buscada por Bergson se resuelve en la noción de «impulso vital», mediante la cual, como creación continua, la "materia» se deshace y asciende organizando la vida a través de la misma. Lo mismo ocurre en el hombre, cuyo espíritu asciende y se libera de la materia que lo aprisiona en un proceso temporal irreversible. Así, aun reconociendo el «monismo» de Bergson, valora que con su voluntad de síntesis acabe afirmando la liberación del espíritu sobre la materia como el secreto íntimo y esencial de la vida del hombre.

Por último, Pemartín escribió, sin reparos, que de Les Deus Sources... se desprendía una filosofía de la historia que coincidía, en su fondo, con la que

31 Pemartín (1934b): 425. 
defendía Acción Española. Para su demostración, atendió a la teoría social de la moral y la teoría de las religiones que presentaba la obra. En las sociedades primitivas dominó, según Bergson, una moral instintiva que se traducía en un sentimiento de obligación derivado de la presión del grupo. A esa «moral cerrada» se le opuso una "moral abierta» de vocación universalista. Así, el «impulso vital» evolucionó desde una moral del instinto a una moral de la intuición espiritual, la cual está llamada a superar las circunscripciones de la familia y de la patria en vistas al amor universal. De ese modo, la teoría social de la moral desembocaba en una teoría de la religión, que le llevó a dividir a esta en una religión estática que lastra la moral de los pueblos primitivos y una religión dinámica, de corte universalista. Esta sería obra de unos «individuos privilegiados» en los que surge una «intuición», una actividad espiritualmente superior, un impulso hacia el verdadero fin que no es otro que la divinidad y el amor, ambos esencias del misticismo. Por ello, el único porvenir que puede esperar la humanidad tendría que venir gracias a la propagación de la mística cristiana, cuya dirección coincide con la del «impulso vital». De forma que la orientación salvacionista del misticismo cristiano de Bergson coincide con la del clasicismo católico que de modo particular ha sido representado por España a largo de su historia. Este fue perfectamente defendido por Maeztu en su Defensa de la Hispanidad, donde esta última se presenta como objetivo colectivo, como fin y fundamento de una nación española que ha sido imprescindible para la historia universal ${ }^{32}$.

Este es el modo en que la instrumentalización de la filosofía de Bergson pudo servir tanto para justificar el golpe militar de julio de 1936 o para darle estatus teórico a la propuesta de un "fascismo católico» que Pemartín hizo durante la guerra, incorporándolo a un metarrelato dirigido a establecer la lógica identitaria que legitimó tanto la limpieza política en la zona rebelde como la futura biopolítica del régimen franquista. Y aún operará en la concepción idealizada del papel de España en la historia que se tratará de utilizar como maquillaje ante la comunidad internacional una vez vencidos los fascismos.

\section{CONCLUSIONES}

Algo que tuvieron en común las diferentes formas de irracionalismo que surgieron de las ruinas del pensamiento ilustrado fue el haber despuntado en los países que se encontraban embarcados dentro de la carrera imperialista y

32 Maeztu (2005): LII. 
belicista de comienzos del siglo xx, como fue el caso de Francia. En ellos, algunos filósofos se vieron vinculados a la radicalización de las ideas nacionalistas, contribuyendo al giro autoritario que tuvo lugar tras la Gran Guerra por las lecturas ideológicas que desde determinados sectores se hizo de ellos. En el plano de la teoría, estas alimentaron el desprecio del materialismo y de toda concepción del mundo basada en unos fundamentos racionales y científicos, privilegiando la acción sobre la razón. Por ejemplo, en 1929, Paul Nizan señalaba, comentando en la revista marxista la obra de Georges Politzer Bergsonism, a Philosophical Hoax (Le Bergsonisme, une Mystification Philosophique), de qué modo la filosofía de Bergson era un episodio de la lucha de la burguesía reaccionaria de su tiempo contra la Revolución. Veinte años después, un joven Louis Althusser compararía la reacción del bergsonismo contra la tradición kantiano-hegeliana con la emprendida por Jacobi contra las ideas ilustradas a finales del siglo XVIII, señalando la existencia de dos filosofías: una, la del concepto, que permite discusión racional y demanda argumentación, y otra, la de la intuición, que en última instancia sitúa la posibilidad de acceder a la verdad en un don de Dios, siendo en esencia una filosofía aristocrática y reaccionaria ${ }^{33}$.

Con sus textos, Pemartín estaba incorporando al discurso del subcampo intelectual de la derecha española un tema de trascendencia europea, y las evocaciones del filósofo francés tuvieron que jugar un importante papel ritual en sus numerosas conferencias en los espacios locales en los que se desenvolvió. Del mismo modo que dotaba de actualidad su defensa del tradicionalismo, como importante elaborador teórico en el grupo de los monárquicos que se enfrentaron a la II República, primero, y a la permanencia de Franco, después, colocaba una pieza que permitía el diálogo con los fascismos. Ya por último, Bergson le serviría para su propia singularización intelectual como filósofo empeñado en elaborar una ontología del tiempo propia.

En definitiva, el análisis de la recepción del pensamiento del filósofo francés en el campo intelectual de la extrema derecha española revela la necesidad de estudiar esta en conexión con el contexto cultural y filosófico europeo, así como las redes intelectuales internacionales de las que formaba parte. Por otro lado, muestra que tanto el fascismo como los movimientos autoritarios y reaccionarios que marcaron la vida social y política de la Europa de entreguerras no se pueden entender únicamente desde el estudio de las estructuras, prácticas o regímenes, prescindiendo de las ideas — vehiculadas, entre otros medios, en textos que hay que interpretar adecuadamente- que mantenían en movimiento a sus agentes. Por último, se muestra la fecundidad del

33 Vermeren (2006): 165-166. 
análisis de las trayectorias de pensadores menores y cómo en ellos se reflejan de modo muy realista los contornos de una época.

La cooperación entre disciplinas, en este caso, la historia y la filosofía, puede traer consigo una práctica inteligente de ambas a la hora de producir conocimiento crítico sobre los procesos y acontecimientos del pasado. Respecto a Bergson, que nunca fue afín a la extrema derecha y seguiría odiado por amplios sectores del nacionalcatolicismo español, cabe decir que al igual que otros, como el propio Nietzsche o quien nublará totalmente su figura, Martin Heidegger, es un autor polifónico que permite lecturas y usos diversos, tal y como por ejemplo se pueden localizar en el papel fundamental que jugará en la filosofía de Gilles Deleuze o Félix Guattari décadas después, cuyas posturas fueron diametralmente opuestas a la cultura política que Pemartín contribuyó a actualizar.

\section{Bibliografía}

Antliff, M. (1993). Inventing Bergson. Cultural Politics and the Parisian Avant-Garde. Princeton: Princeton University Press.

Atencia, J. M. (2003). Razón, intuición y experiencia de la vida. Coincidencia y divergencias entre H. Bergson y J. Ortega y Gasset. Logos. Anales del Seminario de Metafísica, $36,67-98$.

Bergson, H. (1973). La evolución creadora. Madrid: Espasa-Calpe.

— (2004). Duración y simultaneidad (A propósito de la teoría de Einstein). Buenos Aires: P.U.F.

Castro Sánchez, Á. (2013). Filosofía y ciencia en el pensamiento reaccionario español durante la II República. La figura de José Pemartín. Éndoxa: Series Filosóficas, 32, 133-152.

- (2018). La utopia reaccionaria de José Pemartín y Sanjuán (1888-1954). Una historia genética de la derecha española. Cádiz: Universidad de Cádiz.

Cerezo Galán, P. (2003). El mal del siglo. El conflicto entre Ilustración y Romanticismo en la crisis finisecular del siglo XIX. Madrid: Biblioteca Nueva.

Gallego, F. (2014). El evangelio fascista. La formación de la cultura politica del Franquismo (1930-1950). Barcelona: Crítica.

Gilson, É. (1962). El filósofo y la teología. Madrid: Guadarrama.

Giocanti, S. (2008). Charles Maurras: Le chaos et l'ordre. Paris: Flammarion.

González Cuevas, P. C. (1998). Acción Española. Teología politica y nacionalismo autoritario en España (1913-1936). Madrid: Tecnos.

- (2001). Las tradiciones ideológicas de la extrema derecha espańola. Hispania, 207, 99-141. Disponible en: https://doi.org/10.3989/hispania.2001.v61.i207.308.

Griffin, R. (2010). Modernismo y fascismo. La sensación de comienzo bajo Mussolini y Hitler. Madrid: Akal.

Lacau ST Guily, C. (2015). Henry Bergson en Espagne. Une histoire contrariée (1875-1930). Paris: Editions L'Harmattan. 
- (2010). Une histoire contrariée du bergsonisme en Espagne (1889-années 1920). Alicante: Biblioteca Cervantes Virtual.

López Íñiguez, J. (2010). El nacionalcatolicismo de José Pemartín. Almería: Círculo Rojo.

Lukács, G. (1972). El asalto a la razón. La trayectoria del irracionalismo desde Schelling hasta Hitler. México D.F.: Grijalbo.

Maeztu, Ramiro de (2005). Defensa de la Hispanidad. Madrid: Homo Legens.

Ortega y Gasset, J. (2005). Obras Completas. Tomo III. Madrid: Taurus, Fundación José Ortega y Gasset-Gregorio Marañón.

Morodo, R. (1985). Los orígenes ideológicos del Franquismo: Acción Española. Madrid: Alianza.

Olabarría Agra, J. (1990). Fuentes francesas de Acción Española. Historia contemporánea, 3, 219-238.

Pemartín, J. (1928). Los valores históricos en la dictadura española. Madrid: Arte y Ciencia.

- (1932). La Física y el Espíritu III. Acción Española, 20, 131-146.

— (1934a). Vida cultural. Acción Española, 42, 594-595.

- (1934b). Cultura y nacionalismo. Acción Española, 66-67, 600-601.

- (1941). Introducción a una filosofía de lo temporal. Doce lecciones sobre Espacio-Tiempo-Causalidad. Madrid: Espasa-Calpe.

Quiroga Fernández, A. (2007). Los orígenes del nacional-catolicismo. José Pemartín y la Dictadura de Primo de Rivera. Granada: Comares.

Saz, I. (2012). ¿¿Dónde está el otro? O sobre qué eran los que no eran fascistas. En J.A. Mellón (comp.). El fascismo clásico (1919-1945) y sus epígonos, (pp. 155-190). Madrid: Tecnos.

Sternhell, Z., Sznajder, M. y Asheri, M. (1994). El nacimiento de la ideología fascista. Madrid: Siglo XXI.

Vermeren, P. (2006). ¿Decadencia y muerte del bergsonismo? En H. González y P. Vermeren (eds.). ¿Inactualidad del bergsonismo? (pp.197-208). Buenos Aires: Colihue.

Vidler, A. (1970). A variety of Catholic Modernist. London: Camdridge University Press.

Zaragüeta, J. (1941). La intuición en la filosofía de Henri Bergson. Madrid: Espasa-Calpe. 